\title{
A docência, seus saberes e os processos de formação do professor de biologia: uma revisão de literatura
}

\author{
The teaching, their knowledge and biology teacher training processes: a \\ literature review
}

\section{La docencia, sus saberes y los procesos de formación del docente de biología: una revisión de la literatura}

\author{
Willian da Silva Medeiros (wsm1903@gmail.com) \\ Instituto Federal de Educação, Ciência e Tecnologia Farroupilha - IFFar \\ Vantoir Roberto Brancher (vantoir.brancher@iffarroupilha.edu.br) \\ Instituto Federal de Educação, Ciência e Tecnologia Farroupilha - IFFar \\ Neiva Maria Frizon Auler (n.auler@iffarroupilha.edu.br) \\ Instituto Federal de Educação, Ciência e Tecnologia Farroupilha - IFFar
}

\begin{abstract}
Resumo: Esta pesquisa bibliográfica, de natureza teórica, foi realizada através de uma revisão de literatura das dissertações e teses publicadas na Biblioteca Digital Brasileira de Teses e Dissertações - BDTD, que teve por objetivo mapear o que tem sido pesquisado sobre os saberes produzidos e mobilizados por professores de Biologia enquanto elementos da formação desses profissionais. A partir dos critérios de busca e seleção foram encontradas 18 produções de interesse para esta investigação. Com o mapeamento e análise das dissertações e teses foi possível identificar uma grande diversidade de trabalhos, de abordagens e de propostas que emergiram deste cenário analisado. Identificamos que, em sua maioria, as produções contemplaram os processos de formação inicial de professores nas licenciaturas e espaços específicos. Salientamos a incipiência dos estudos voltados à formação do professor de Biologia para a Educação Profissional e Tecnológica ${ }^{1}$, de modo que apenas uma produção abordou a formação do professor de Biologia neste contexto.
\end{abstract}

Palavras-chave: Biologia; Saberes Docentes; Formação de professores.

Abstract: This bibliographic research, with theorical nature, was conducted through a literature review of dissertations and theses published in the Brazilian Digital Library of Theses and Dissertations - BDTD, which aimed to map what has been researched on the knowledge produced and mobilized by teachers of Biology as elements of the training of these professionals. From the search and selection criteria were found 18 productions of interest for

\footnotetext{
${ }^{1}$ Embora este trabalho esteja incluído em uma pesquisa do campo da Educação Profissional e Tecnológica intitulada "Trajetos formativos e saberes docentes: ressignificando a docência de biologia na Educação Profissional e Tecnológica", destacamos que na ocasião das buscas não obtivemos resultados de produções com os descritores específicos para "Educação Profissional". A única produção que problematiza a docência de Biologia na EPT emergiu quando retiramos estes descritores específicos, situação que justifica a necessidade de pesquisas que abordem temáticas nesta especificidade da atuação docente.
}

Recebido em: 30/05/2021

Aceite em: 13/08/2021 
this investigation. With the mapping and analysis of dissertations and theses it was possible to identify a great diversity of works, approaches and proposals that emerged from this analyzed scenario. We identified that most of the productions contemplated the processes of initial teacher education in graduation courses and in specific spaces. We emphasize the incipience of studies focused on the formation of the Biology teacher for Professional and Technological Education, so that only one production addressed the formation of the Biology teacher in this context.

Keywords: Biology; Teaching Knowledge; Teacher education.

Resumen: Esta investigación bibliográfica, de carácter teórico, se realizó a través de una revisión bibliográfica de las disertaciones y tesis publicadas en la Biblioteca Digital Brasileña de Tesis y Disertaciones - BDTD, que tuvo como objetivo mapear lo investigado sobre los saberes producidos y movilizados por los docentes de la Biología como elementos de la formación de estos profesionales. A partir de los criterios de búsqueda y selección se encontraron 18 producciones de interés para esta investigación. Con el mapeo y análisis de disertaciones y tesis fue posible identificar una gran diversidad de trabajos, enfoques y propuestas que surgieron de este escenario analizado. Encontramos que, en su mayor parte, las producciones incluyeron los procesos de formación inicial docente en cursos de pregrado y espacios específicos. Destacamos la incipiencia de estudios orientados a la formación del docente de Biología para la Educación Profesional y Tecnológica, por lo que solo una producción abordó la formación del docente de Biología en este contexto.

Palabras-clave: Biología; Saberes docentes; Formación de professores.

\section{INTRODUÇÃO}

O desenvolvimento científico e tecnológico tem sido habitualmente identificado como responsável por profundas transformações em nossas vidas, possibilitando a resolução para muitos questionamentos humanos e alterando, de forma significativa, os nossos modos de compreender e de estar no mundo.

A educação científica enfrenta, desta forma, um importante desafio para a construção de conhecimentos que subsidiem a busca pela formação crítica dos sujeitos. Para tanto, Silva e Bastos (2012) destacam no desenvolvimento profissional dos professores um significativo instrumento para a efetivação de uma educação científica que atenda à abrangência dos objetivos que lhes são atribuídos.

As áreas de pesquisas em Ensino de Ciências têm se constituindo no Brasil a partir da segunda metade do século XX e, desde então, vem se consolidando de forma bastante significativa no cenário acadêmico, contando com uma comunidade científica bastante atuante

Recebido em: 30/05/2021

Aceite em: 13/08/2021 
e distribuída em diversos programas de pós-graduação (OLIVEIRA et al., 2021; SANTOS, 2007). Neste contexto, Moryama, Passos e Arruda (2013) destacam as pesquisas que problematizam a formação de professores como uma das áreas mais antigas e mais investigadas para no Ensino de Ciências, constituindo importante subsídio para a construção de saberes e o desenvolvimento da docência nestas áreas do conhecimento.

Pesquisas que buscam a elucidação dos saberes construídos e mobilizados na docência são compreendidas como uma empreitada de significativa importância, uma vez que tais saberes são reconhecidos como os alicerces da prática docente, sendo assim componentes cruciais para a qualificação das práticas educativas, bem como na constituição e consolidação da condição profissional do professor (GAUTHIER et al., 2013).

Estudos referentes ao campo dos saberes docentes têm ganhado cada vez mais espaço e visibilidade no cenário das ciências da educação como um todo. Em um resgate sobre a constituição deste campo de estudos, Borges e Tardif (2001) identificaram um crescimento exponencial das publicações que problematizam temáticas relativas aos saberes dos professores, estabelecendo um campo de estudos bastante rico e diverso do ponto de vista teórico e metodológico.

Cunha (2013) destaca que as questões relativas aos saberes docentes têm cada vez mais se mostrado presentes no campo da formação de professores buscando, no reconhecimento da prática docente como instância produtora de saberes, a superação da racionalidade técnica que historicamente permeou os processos formativos destes profissionais e afastou o seu desenvolvimento dos contextos de sua atuação.

A partir do exposto, buscamos neste estudo de estado da arte investigar as formas como a produção acadêmica em nível de pós-graduação tem trabalhado os aspectos relativos à construção e mobilização dos saberes docentes enquanto elementos dos processos de formação do professor de Biologia.

\section{METODOLOGIA}

Em relação aos aspectos metodológicos desta investigação, observamos esta como um trabalho de cunho qualitativo, uma vez que busca compreender aspectos relativos à produção 
do conhecimento no campo educativo (TRIVIÑOS, 1987). Esta pesquisa pode também ser caracterizada como bibliográfica de caráter exploratório, como descrito por Severino (2007), visto que buscamos levantar informações acerca da manifestação de nosso objeto de análise, com o objetivo de identificar os modos como as pesquisas acadêmicas na pós-graduação têm apresentado os saberes docentes enquanto fundamentos para os processos de formação do professor de biologia.

Nos aproximamos dos procedimentos apresentados por Romanowski e Ens (2006) para a realização de um estudo de estado da arte. Dentre estes procedimentos destacamos a seleção dos descritores que orientam as buscas, a especificação do catálogo fonte, o estabelecimento dos critérios de composição do corpus, a leitura e a sistematização das produções

Para a elaboração desta investigação foram realizadas buscas na Biblioteca Digital Brasileira de Teses e Dissertações - BDTD, vinculada ao Instituto de Informação em Ciência e Tecnologia - IBICT. As buscas foram realizadas com o auxílio dos filtros de dados presentes na plataforma que auxiliaram no refinamento dos dados, nestes utilizamos os descritores: "Saberes docentes"; "Formação de professores"; e "Biologia". Estes termos foram atribuídos concomitantemente na busca e utilizados para todos os campos disponíveis para procura (título, autor, assunto, resumo português, resumo inglês, editor e ano de defesa).

A partir desta busca emergiram 47 produções, destas, 32 dissertações e 15 teses defendidas entre os anos de 2004 e 2020. Após a leitura dos resumos destas produções e identificar aquelas que se aproximavam da temática foco desta investigação, obteve-se uma redução no número de produções para um total de 18 trabalhos, constituindo assim o corpus dessa investigação. Descrita por Ghedin (2004) como um significativo instrumento metodológico capaz de possibilitar uma leitura mais abrangente e totalizante da realidade expressa nos discursos, a hermenêutica se mostrou como uma possibilidade de análise deste conjunto de dissertações e teses. A partir disto, nos aproximamos dos pressupostos da hermenêutica de Ricoeur (1990, p. 17), que a define como "a teoria das operações da compreensão em sua relação com a interpretação dos textos", como dispositivo metodológico para a análise e compreensão dos sentidos presentes nos textos de nosso corpus investigativo.

As 29 produções que não foram selecionadas para fazer parte desta análise abordavam temáticas que não se aproximavam das deste estudo, tais como: formação inicial e continuada 
de professores dos anos iniciais para o ensino de ciências e matemática; ensino de estatística; práticas inclusivas e ensino de química; e, estudos bibliográficos e documentais.

\section{RESULTADOS E DISCUSSÃO}

\subsection{Mapeamento das produções encontradas}

A partir da leitura dos resumos das produções e a respectiva seleção daquelas que apresentam sua temática aproximada à deste trabalho foram selecionadas 18 produções, constituindo uma amostra de 13 dissertações e 5 teses.

Tabela 1 - Distribuição das teses e dissertações selecionadas por ano.

\begin{tabular}{cccc}
\hline Ano de defesa & Dissertação & Tese & Total por ano \\
\hline $\mathbf{2 0 0 4}$ & 0 & 0 & 0 \\
$\mathbf{2 0 0 5}$ & 0 & 1 & 1 \\
$\mathbf{2 0 0 6}$ & 0 & 0 & 0 \\
$\mathbf{2 0 0 7}$ & 0 & 0 & 0 \\
$\mathbf{2 0 0 8}$ & 1 & 0 & 1 \\
$\mathbf{2 0 0 9}$ & 0 & 0 & 0 \\
$\mathbf{2 0 1 0}$ & 1 & 0 & 1 \\
$\mathbf{2 0 1 1}$ & 0 & 0 & 0 \\
$\mathbf{2 0 1 2}$ & 1 & 0 & 1 \\
$\mathbf{2 0 1 3}$ & 1 & 0 & 1 \\
$\mathbf{2 0 1 4}$ & 3 & 0 & 3 \\
$\mathbf{2 0 1 5}$ & 2 & 1 & 3 \\
$\mathbf{2 0 1 6}$ & 2 & 1 & 3 \\
$\mathbf{2 0 1 7}$ & 1 & 0 & 1 \\
$\mathbf{2 0 1 8}$ & 1 & 2 & 3 \\
$\mathbf{2 0 1 9}$ & 0 & 0 & 0 \\
$\mathbf{2 0 2 0}$ & 0 & 0 & 0 \\
\hline Total por nível & $\mathbf{1 3}$ & $\mathbf{5}$ & $\mathbf{1 8}$ \\
\hline & Fonte: Os autores, 2020. &
\end{tabular}

Na Tabela 1 identificamos as 18 produções investigadas neste estudo, destacando a quantidade de dissertações e de teses defendidas por ano. Nesta tabela fica evidenciada a presença de 13 dissertações e 5 teses entre os anos de 2005 e 2018, percebe-se também um vazio nas produções nesta temática específica nos anos de 2006, 2007, 2009 e 2011, de modo que nenhuma dissertação e nenhuma tese foram defendidas nestes anos. Este comportamento se mostra similar ao evidenciado por Fabrício e Martins (2017) em sua análise de artigos científicos sobre a formação de professores de Ciências e Biologia. De acordo com os autores, 
uma possível explicação para este fenômeno passa pelo estabelecimento, no ano de 2011, das diretrizes do Plano Nacional de Educação - PNE para o decênio 2011-2020, uma política que impacta diretamente a formação de professores, podendo assim ter instigado o interesse de pesquisadores da temática.

Outra característica desta amostra de produções é a lacuna de teses defendidas entre os anos de 2006 e 2014, mostrando que, em um período de 17 anos analisados, em apenas 4 destes foram defendidas teses de doutorado nesta temática.

Esta situação aponta para a necessidade de mais teses de doutorado nesta temática, uma vez que, pelo aprofundamento das pesquisas neste nível, estas produções poderiam se constituir como importantes referenciais para este campo de estudos.

A Tabela 2 busca mostrar as Instituições de Ensino Superior - IES e os respectivos Programas de Pós-Graduação - PPG que contribuíram para a produção de conhecimento nesta temática de investigação.

Tabela 2 - Quantidade de produções por IES e PPG

\begin{tabular}{|c|c|c|c|c|c|}
\hline IES & PPG & Dissertações & Teses & $\begin{array}{c}\text { Total } \\
\text { do PPG }\end{array}$ & $\begin{array}{r}\text { Total } \\
\text { da IES }\end{array}$ \\
\hline IFAM & $\begin{array}{l}\text { Programa de Pós-Graduação do Mestrado } \\
\text { Profissional em Ensino Tecnológico }\end{array}$ & 1 & 0 & 1 & 1 \\
\hline PUC-RIO & Programa de Pós-Graduação em Educação & 0 & 1 & 1 & 1 \\
\hline UFABC & $\begin{array}{l}\text { Programa de Pós-Graduação em Ensino, } \\
\text { História e Filosofia das Ciências e } \\
\text { Matemática }\end{array}$ & 1 & 0 & 1 & 1 \\
\hline UFAM & $\begin{array}{l}\text { Programa de Pós-Graduação em Ensino de } \\
\text { Ciências e Matemática }\end{array}$ & 1 & 0 & 1 & 1 \\
\hline UFBA & Programa de Pós-Graduação em Educação & 1 & 0 & 1 & 1 \\
\hline UFC & $\begin{array}{l}\text { Programa de Pós-Graduação em Educação } \\
\text { Brasileira }\end{array}$ & 1 & 0 & 1 & 1 \\
\hline UFMA & $\begin{array}{l}\text { Programa de Pós-Graduação em Ensino de } \\
\text { Ciências e Matemática }\end{array}$ & 1 & 0 & 1 & 1 \\
\hline UFMG & Programa de Pós-Graduação em Educação & 2 & 0 & 2 & 2 \\
\hline UFMT & Programa de Pós-Graduação em Educação & 1 & 0 & 1 & 1 \\
\hline UFPEL & $\begin{array}{l}\text { Programa de Pós-Graduação no Ensino de } \\
\text { Ciências e Matemática }\end{array}$ & 1 & 0 & 1 & 1 \\
\hline UFRGS & $\begin{array}{l}\text { Programa de Pós-Graduação em Educação } \\
\text { em Ciências: Química da Vida e Saúde }\end{array}$ & 0 & 1 & 1 & 1 \\
\hline UFRPE & $\begin{array}{l}\text { Programa de Pós-Graduação em Ensino das } \\
\text { Ciências }\end{array}$ & 0 & 2 & 2 & 2 \\
\hline
\end{tabular}

Recebido em: 30/05/2021

Aceite em: 13/08/2021 


\begin{tabular}{c|l|c|c|c|c}
\hline \multirow{2}{*}{ UFSC } & $\begin{array}{l}\text { Programa de } \\
\text { Pós-Graduação em Educação Científica e } \\
\text { Tecnológica }\end{array}$ & 1 & 0 & 1 & \multirow{1}{*}{$\mathbf{1}$} \\
\hline \multirow{3}{*}{ USP } & Programa de Pós-Graduação em Botânica & 1 & 0 & 1 & \multirow{2}{*}{$\mathbf{3}$} \\
\cline { 2 - 5 } & $\begin{array}{l}\text { Programa de Pós-Graduação Interunidades } \\
\text { em Ensino de Ciências }\end{array}$ & 1 & 0 & 1 & 1 \\
\cline { 2 - 5 } & Programa de Pós-Graduação em Educação & 0 & 1 & 1 & \multirow{1}{*}{$\mathbf{1 8}$} \\
\hline
\end{tabular}

Fonte: Os autores, 2020.

A partir dos dados apresentados na Tabela 2 se percebe que a IES que mais colaborou com produções na temática foi a Universidade de São Paulo, com 3 trabalhos desenvolvidos, seguida pela Universidade Federal de Minas Gerais e a Universidade Federal Rural de Pernambuco, estas com 2 produções cada. As demais IES contribuíram com uma produção.

No que se refere aos PPGs, observou-se que o Programa de Pós-Graduação em Educação da UFMG e o Programa de Pós-Graduação em Ensino das Ciências da UFRPE apareceram com duas produções, todos os demais contribuíram com uma produção cada. A partir disto se percebe que a temática não se mostra como campo de investigação perene nos diversos PPGs, mas como investigações infrequentes e isoladas nestes espaços.

Este levantamento das produções acadêmicas em nível de mestrado e doutorado na BDTD sobre a temática dos saberes de professores de biologia como elementos constituintes de processos da formação docente, nos possibilitou organizar este panorama geral das produções. A seguir apresentamos a descrição das produções selecionadas para este estudo a fim de compreender como a temática tem se desenvolvido no cenário acadêmico.

\subsection{Descrição das produções selecionadas}

Nesta etapa serão trazidas as descrições das 18 produções selecionadas a partir dos parâmetros já mencionados. Estas produções foram sistematizadas no Quadro 1 através do nome do(a) autor(a), título da produção, IES, PPG, tipo de produção e ano de defesa, com ordenação crescente de ano de defesa.

Quadro 1 - Sistematização das produções selecionadas para descrição.

\begin{tabular}{|l|l|l|l|l|l|}
\hline Autor(a) & Título & IES & PPG & Tipo & Ano \\
\hline
\end{tabular}




\begin{tabular}{|c|c|c|c|c|c|}
\hline $\begin{array}{l}\text { Rosana dos } \\
\text { Santos } \\
\text { Jordão }\end{array}$ & $\begin{array}{l}\text { Tutoria e pesquisa-ação no estágio } \\
\text { supervisionado: contribuições para a } \\
\text { formação de professores de biologia. }\end{array}$ & USP & $\begin{array}{l}\text { Programa de Pós- } \\
\text { Graduação em } \\
\text { Educação }\end{array}$ & Tese & 2005 \\
\hline $\begin{array}{l}\text { Fernanda } \\
\text { Reis de } \\
\text { Pinho } \\
\text { Tavares }\end{array}$ & $\begin{array}{l}\text { Profissãa docente: visões de licenciandos } \\
\text { de ciências biológicas em diferentes } \\
\text { contextos }\end{array}$ & UFMG & $\begin{array}{l}\text { Programa de Pós- } \\
\text { Graduação em } \\
\text { Educação }\end{array}$ & Dissertação & 2008 \\
\hline $\begin{array}{l}\text { Mariana } \\
\text { Leal } \\
\text { Oliveira de } \\
\text { Sa Carvalho } \\
\end{array}$ & $\begin{array}{l}\text { A abordagem das questões ambientais } \\
\text { como forma de inserção da educação } \\
\text { ambiental no ensino de ciências }\end{array}$ & UFMG & $\begin{array}{l}\text { Programa de Pós- } \\
\text { Graduação em } \\
\text { Educação }\end{array}$ & Dissertação & 2010 \\
\hline $\begin{array}{l}\text { Helder } \\
\text { Antonio de } \\
\text { Freitas }\end{array}$ & $\begin{array}{l}\text { Saberes docentes pedagógicos } \\
\text { computacionais e sua elaboração na } \\
\text { prática }\end{array}$ & USP & $\begin{array}{l}\text { Programa de Pós- } \\
\text { Graduação em } \\
\text { Educação }\end{array}$ & Dissertação & 2012 \\
\hline $\begin{array}{l}\text { Marfa } \\
\text { Magali } \\
\text { Roehrs }\end{array}$ & $\begin{array}{l}\text { Licenciatura em Ciências Biológicas: } \\
\text { uma análise dos saberes de referência e } \\
\text { pedagógicos na formação de professores } \\
\text { para os anos finais do ensino fundamental }\end{array}$ & UFMT & $\begin{array}{l}\text { Programa de Pós- } \\
\text { Graduação em } \\
\text { Educação }\end{array}$ & Dissertação & 2013 \\
\hline $\begin{array}{l}\text { Ingrid } \\
\text { Caroline de } \\
\text { Almeida Zia }\end{array}$ & $\begin{array}{l}\text { Estudo da formação inicial sob a } \\
\text { dimensão dos saberes docentes e do } \\
\text { ensino de ciências por investigação }\end{array}$ & UFABC & $\begin{array}{c}\text { Programa de Pós- } \\
\text { Graduação em } \\
\text { Ensino, História e } \\
\text { Filosofia das Ciências } \\
\text { e Matemática } \\
\end{array}$ & Dissertação & 2014 \\
\hline $\begin{array}{l}\text { Elisa de } \\
\text { Araújo Gallo }\end{array}$ & $\begin{array}{l}\text { A Construção da profissionalidade } \\
\text { docente dos licenciandos em biologia, } \\
\text { física e química: mediação, saberes } \\
\text { docentes e lúdico-sensíveis }\end{array}$ & UFBA & $\begin{array}{l}\text { Programa de Pós- } \\
\text { Graduação em } \\
\text { Educaçãao }\end{array}$ & Dissertação & 2014 \\
\hline $\begin{array}{l}\text { Thierry } \\
\text { Faria Lima }\end{array}$ & $\begin{array}{l}\text { A temática algas na formação continuada } \\
\text { de professores de Biologia: uma } \\
\text { experiência na Educação a Distância }\end{array}$ & USP & $\begin{array}{l}\text { Programa de Pós- } \\
\text { Graduação em } \\
\text { ciências Biológicas }\end{array}$ & Dissertação & 2014 \\
\hline $\begin{array}{l}\text { Caciele } \\
\text { Guerch } \\
\text { Gindri de } \\
\text { Bastos }\end{array}$ & $\begin{array}{l}\text { Iniciando a docência: a construção do } \\
\text { perfil profissional na visão dos futuros } \\
\text { professores de ciências da UFPEL }\end{array}$ & UFPEL & $\begin{array}{l}\text { Programa de Pós- } \\
\text { Graduação no Ensino } \\
\text { de Ciências e } \\
\text { Matemática } \\
\end{array}$ & Dissertação & 2015 \\
\hline $\begin{array}{l}\text { Fernanda } \\
\text { Muniz } \\
\text { Brayner } \\
\text { Lopes }\end{array}$ & $\begin{array}{l}\text { Formação de docentes universitários: um } \\
\text { complexo de interações paradigmáticas }\end{array}$ & UFRPE & $\begin{array}{l}\text { Programa de Pós- } \\
\text { Graduação em Ensino } \\
\text { de Ciências }\end{array}$ & Tese & 2015 \\
\hline $\begin{array}{l}\text { Elisa } \\
\text { Margarita } \\
\text { Orlandi }\end{array}$ & $\begin{array}{l}\text { A prática pedagógica como componente } \\
\text { curricular na formação de professores: a } \\
\text { visão de graduandos do curso de Ciências } \\
\text { Biológicas (diurno) da Universidade } \\
\text { Federal de Santa Catarina }\end{array}$ & UFSC & $\begin{array}{l}\text { Programa de Pós- } \\
\text { Graduação em } \\
\text { Educação Científica e } \\
\text { Tecnológica } \\
\end{array}$ & Dissertação & 2015 \\
\hline $\begin{array}{l}\text { Ana Lucia } \\
\text { Gomes } \\
\text { Cavalcanti } \\
\text { Neto } \\
\end{array}$ & $\begin{array}{l}\text { Relações entre saberes e ações na } \\
\text { constituição da atividade e prática } \\
\text { docentes de professores de ciências }\end{array}$ & UFRPE & $\begin{array}{c}\text { Programa de Pós- } \\
\text { Graduação em Ensino } \\
\text { de Ciências e } \\
\text { Matemática } \\
\end{array}$ & Tese & 2016 \\
\hline $\begin{array}{l}\text { Fernanda } \\
\text { Rebeca } \\
\text { Araújo da } \\
\text { Silva } \\
\end{array}$ & $\begin{array}{l}\text { Saberes docentes na formação inicial de } \\
\text { professores para a educação profissional } \\
\text { técnica de nível médio }\end{array}$ & IFAM & $\begin{array}{l}\text { Programa de Pós- } \\
\text { Graduação em Ensino } \\
\text { Tecnológico }\end{array}$ & Dissertação & 2016 \\
\hline $\begin{array}{l}\text { Edilene da } \\
\text { Silva Souza }\end{array}$ & $\begin{array}{l}\text { Saberes docentes produzidos e } \\
\text { mobilizados na formação de professores } \\
\text { de Ciências Biológicas em cursos de } \\
\text { graduação do PARFOR/UFAM }\end{array}$ & UFAM & $\begin{array}{c}\text { Programa de Pós- } \\
\text { Graduação em Ensino } \\
\text { de Ciências e } \\
\text { Matemática }\end{array}$ & Dissertação & 2016 \\
\hline
\end{tabular}




\begin{tabular}{|c|c|c|c|c|c|}
\hline $\begin{array}{c}\text { Karla Jeane } \\
\text { Coqueiro } \\
\text { Bezerra }\end{array}$ & $\begin{array}{l}\text { Saberes docentes e suas relações com a } \\
\text { construção de movimentos epistêmicos } \\
\text { desenvolvidos em aulas de Biologia }\end{array}$ & UFMA & $\begin{array}{c}\text { Programa de Pós- } \\
\text { Graduação em Ensino } \\
\text { de Ciências e } \\
\text { Matemática } \\
\end{array}$ & Dissertação & 2017 \\
\hline $\begin{array}{c}\text { Raquel } \\
\text { Alexandre } \\
\text { Pinho dos } \\
\text { Santos } \\
\end{array}$ & $\begin{array}{l}\text { Resistências e emergências nas } \\
\text { licenciaturas de Biologia: discursos e } \\
\text { práticas sobre sexualidade e gênero }\end{array}$ & $\begin{array}{c}\text { PUC- } \\
\text { RIO }\end{array}$ & $\begin{array}{l}\text { Programa de Pós- } \\
\text { Graduação em } \\
\text { Educação }\end{array}$ & Tese & 2018 \\
\hline $\begin{array}{c}\text { Maria } \\
\text { Cleidiane } \\
\text { Barbosa da } \\
\text { Silva }\end{array}$ & $\begin{array}{l}\text { O museu de ciência como cenário da } \\
\text { formação docente: saberes e concepções } \\
\text { de licenciandos mediadores do Museu } \\
\text { Seara da Ciência - UFC }\end{array}$ & UFC & $\begin{array}{l}\text { Programa de Pós- } \\
\text { Graduação em } \\
\text { Educação Brasileira }\end{array}$ & Dissertação & 2018 \\
\hline $\begin{array}{l}\text { Elizângela } \\
\text { Beneval } \\
\text { Bento }\end{array}$ & $\begin{array}{l}\text { Avaliação da aplicação de uma } \\
\text { ferramenta pedagógica para o estudo do } \\
\text { fumo passivo com os licenciandos em } \\
\text { biologia da Universidade Regional do } \\
\text { Cariri, CE }\end{array}$ & UFRGS & $\begin{array}{l}\text { Programa de Pós- } \\
\text { Graduação em } \\
\text { Educação em } \\
\text { Ciências: Química da } \\
\text { Vida e Saúde }\end{array}$ & Tese & 2018 \\
\hline
\end{tabular}

Fonte: Os autores, 2020.

Iniciamos a descrição das produções com a tese intitulada Tutoria e pesquisa-ação no estágio supervisionado: contribuições para a formação de professores de biologia, de autoria de Rosana dos Santos Jordão. Este estudo teve por objetivo analisar como o estágio supervisionado, coletivo e concebido a partir dos referenciais da prática reflexiva, poderia colaborar para a formação dos saberes docentes de licenciandos de Ciências Biológicas. Neste contexto, a própria autora da investigação era a tutora do estágio.

Do ponto de vista metodológico, a investigação se deu através das abordagens qualitativas por meio de um enfoque interpretativo. Os dados foram coletados a partir da observação das aulas ministradas pelos estagiários, de dois questionários de avaliação do estágio por parte dos estudantes, de entrevistas semiestruturadas com foco na coleta de informações sobre o que estes pensavam sobre a sua aprendizagem e gravações em vídeo das reuniões realizadas com o grupo.

A autora identificou que esta proposta de estágio trouxe importantes contribuições para a construção dos saberes profissionais dos estagiários, embora reconheça, nestas análises, que os saberes referentes ao currículo e às especificidades dos processos educacionais não foram tão favorecidos com a aplicação desta proposta. Uma das possíveis causas apontadas para estas fragilidades se refere à condução das atividades no ciclo de reflexões, que se baseavam em parâmetros técnicos da docência e favoreciam o desenvolvimento dos saberes disciplinares, situação que não desencadeou o interesse dos estudantes em temas referentes ao papel social do professor. No entanto, a autora sugere que o desenvolvimento de projetos de estágio baseados na pesquisa-ação pode abrir novas possibilidades formativas ao abrir espaços para momentos de reflexão e coletividade. 
A dissertação Profissão docente: visões de licenciandos de ciências biológicas em diferentes contextos, de autoria de Fernanda Reis do Pinho Tavares, é uma produção que teve por objetivo compreender a visão de licenciandos do curso de Ciências Biológicas a respeito da profissão docente, tendo como contexto da pesquisa a disciplina de Estágio e Monografia.

Metodologicamente, este é um estudo que priorizou os enfoques de cunho qualitativo de orientação naturalista. A coleta de dados foi realizada através de observações das aulas da disciplina, entrevistas com os participantes e um questionário escrito.

Em suas análises, Tavares (2008) identifica a predominância dos saberes referentes ao contexto escolar e às condições do exercício da prática docente. Tal situação provocou um certo estranhamento à pesquisadora, uma vez que na grande maioria dos estudos, os saberes disciplinares se mostram como uma grande fonte de preocupação por parte dos licenciandos. A autora atribui esta situação aos importantes momentos de reflexão dos estudantes aos aspectos sociais do exercício docente, o que influencia positivamente na constituição da identidade profissional destes professores em formação.

A dissertação intitulada A abordagem das questões ambientais como forma de inserção da educação ambiental no ensino de ciências, de Mariana Leal Oliveira de Sá Carvalho, foi uma produção que objetivou compreender como a Educação Ambiental está presente no ensino de ciências através da inserção de questões ambientais nos conteúdos, bem como compreender quais são os saberes docentes que estão envolvidos nestas abordagens.

A pesquisa foi desenvolvida através dos pressupostos da abordagem qualitativa. A coleta de dados se deu através da aplicação de questionário com professores de ciências; observação de aulas e; entrevistas com os professores sujeitos da pesquisa.

Em seus resultados, Carvalho (2010) identifica que os saberes disciplinares foram priorizados pelos licenciandos em suas práticas de ensino, orientandos principalmente por uma abordagem naturalista das questões ambientais. A autora identificou também a mobilização de saberes curriculares e experienciais durante as práticas destes profissionais. Porém, ressalta que, em sua na maioria, as abordagens se mostram descontextualizadas ou limitadas a exemplos, o que, segundo a autora pouco estimulam a reflexão e o debate das questões ambientais.

A dissertação Saberes docentes pedagógicos computacionais e sua elaboração na prática, de autoria de Helder Antonio de Freitas, teve por objetivo compreender como artefatos 
computacionais poderiam colaborar com as práticas educativas de professores de Ciências, Física, Química e Biologia, além de que se a utilização dessas ferramentas tecnológicas possibilita o desenvolvimento de novos saberes por parte destes professores.

Esta investigação se desenvolveu através dos pressupostos da pesquisa qualitativa. As coletas de dados se deram através de entrevistas semiestruturadas e observações das aulas de quatro professores da Escola de Aplicação da Universidade de São Paulo.

Em suas análises o autor ressalta que a categorização de Tardif (2008) serviu de base para a criação de novas categorias de saberes que o autor designou como Saberes Docentes Pedagógicos Computacionais, os quais serviram para fundamentar a compreensão da relação entre os professores e as ferramentas computacionais.

Freitas (2012) considera que a construção destes saberes se constituiu como um movimento bastante significativo, principalmente no contexto em que estes artefatos computacionais se colocam cada vez mais íntimos do cotidiano das pessoas. Neste contexto o autor indica que a escola deve se organizar para uma adequação tecnológica, se constituindo assim como um espaço em que sejam atribuídos sentido educativo a estas ferramentas.

A dissertação Licenciatura em Ciências Biológicas: uma análise dos saberes de referência e pedagógicos na formação de professores para os anos finais do ensino fundamental, de autoria de Marfa Magali Roehrs, objetivou investigar como os saberes da docência são contemplados na Licenciatura em Ciências Biológicas da Universidade Estadual do Mato Grosso.

A pesquisa foi organizada metodologicamente através dos pressupostos qualitativos, tendo o estudo de caso como estratégia de investigação. As coletas de dados se deram através de análise documental e entrevistas. A análise documental se deu sobre os o Projeto Pedagógico da Licenciatura em Ciências Biológicas e os Planos de Curso das disciplinas. As entrevistas foram realizadas com professores que participaram da construção desses documentos.

Tanto os Saberes de Referência quanto os Pedagógicos são percebidos pela autora como componentes fragmentados nos documentos oficiais, em que não foi encontrado nenhum eixo articulador significativo entre teoria e prática para a constituição dos saberes docentes. Estas situações são reconhecidas pela autora como possíveis fragilidades para a construção dos saberes docentes na formação inicial dos licenciandos. Outra circunstância que agrava este 
quadro se dá pela não identificação, a nível documental, de tópicos que tratem as diferentes abordagens e adequações dos conteúdos para os diferentes públicos da educação básica.

Apesar deste quadro, a autora identifica elementos positivos neste percurso. Um desses se refere ao movimento docente durante a reestruturação curricular e metodológica do curso, construindo, neste coletivo, espaços colaborativos de aprendizagem e reflexão.

Ainda no âmbito dos estudos focados nas licenciaturas em Ciências Biológicas, apresentamos a dissertação intitulada Estudo da formação inicial sob a dimensão dos saberes docentes e do ensino de ciências por investigação. Esta produção, de autoria de Ingrid Caroline de Almeida Zia, objetivou investigar os processos formativos de licenciandos de Ciências Biológicas da Universidade Federal do ABC no que se refere aos saberes docentes construídos e mobilizados no âmbito do ensino de ciências por investigação dos acadêmicos do Programa Institucional de Bolsa de Iniciação à Docência - Pibid.

Do ponto de vista metodológico, esta produção utilizou dos pressupostos qualitativos, sendo caracterizada pela autora como um estudo de caso desenvolvido em um contexto específico da formação de professores, o Pibid de Biologia. Os dados foram coletados através de entrevistas com os acadêmicos e dos relatórios e planos de ensino escritos pelos estudantes.

A autora identificou, tanto das entrevistas quanto dos documentos produzidos pelos licenciandos, manifestações ingênuas sobre a prática docente, que desconsideram a complexidade da ação do professor e do papel deste na mediação do conhecimento e da autonomia dos estudantes. Tais manifestações priorizaram um enfoque praticamente exclusivo na figura do aluno, relegando todas as demais dimensões que compõem o ato educativo ao segundo plano, o que pode fragilizar a construção de saberes por parte destes acadêmicos.

Embora estas situações, a autora ressalta a importância do projeto Pibid no contexto de formação inicial de professores de Biologia como espaço de pesquisa e troca de experiências e, por estar se construindo através de uma concepção de ensino por investigação, vem se tornando um importante instrumento para a construção de saberes para estes estudantes.

A dissertação intitulada A Construção da profissionalidade docente dos licenciandos em biologia, física e química: mediação, saberes docentes e lúdico-sensíveis, de autoria de Elisa de Araújo Gallo, foi uma produção que objetivou compreender o papel dos professores dos institutos específicos na construção da profissionalidade dos licenciandos através de suas 
mediações, seus saberes pedagógicos e lúdico-sensíveis. Estes últimos descritos pela autora como aqueles relacionados à mobilização da arte, da criatividade, das experiências lúdicas, estéticas e afetivas na prática educativa.

Do ponto de vista metodológico, esta produção assume os pressupostos da pesquisa qualitativa de natureza exploratória, que teve os cursos de Biologia, Química e Física da Universidade Federal da Bahia como espaços de investigação. Os dados foram coletados através de questionários, observações de aulas e entrevistas com professores das áreas específicas dos respectivos cursos.

Em suas análises a autora percebe que, embora os professores identifiquem algumas fragilidades na construção de seus saberes, geralmente atribuídas à ausência de diálogo entre os conhecimentos disciplinares, científicos, didáticos e lúdico-sensíveis, estes profissionais revelaram grande cuidado com suas metodologias e com a aprendizagem dos estudantes. Foi percebido também que estes professores atribuem significativo valor aos saberes experienciais que, em alguns casos, se constituem como a única fonte para o exercício da docência.

No que se refere às práticas destes professores universitários, a autora reconhece o cuidado e a preocupação com a formação dos estudantes, sendo percebida a mobilização de um extenso repertório de saberes e recursos, mas indica que a profissionalidade docente nas áreas das Ciências da Natureza ainda carece de saberes lúdico-sensíveis.

Neste contexto, é sugerido que a formação docente vivencie práticas diversificadas, lúdicas e sensíveis como vias para a superação dos modelos rígidos e padronizados que privilegiam apenas os aspectos técnicos da docência, situação que se aproxima das proposições de Neto, Santana e Shuvartz (2018) e tem se constituindo como uma tendência cada vez mais presente nas produções que problematizam a formação docente.

A dissertação A temática algas na formação continuada de professores de Biologia: uma experiência na Educação a Distância, de autoria de Thierry Faria Lima, é uma produção que objetivou contribuir para a ampliação do conhecimento sobre algas na formação continuada de professores de Biologia através da Educação à Distância.

A contribuição pretendida pelo autor se deu pela elaboração de recursos didáticos que foram utilizados pelo programa de educação à distância da Rede São Paulo de Formação 
Docente. Estes recursos foram aplicados em um curso para professores de Biologia organizado por professores do Instituto de Biociências da Universidade de São Paulo.

Do ponto de vista metodológico, esta investigação se utiliza dos atributos da pesquisa qualitativa, uma vez que, após a aplicação dos recursos didáticos se buscou verificar os possíveis impactos no aprimoramento conceitual e ampliação dos conhecimentos e estratégias de ensino dos professores. A fim de mensurar tal impacto, o autor realizou a coleta de dados através de questionários com os de 36 cursistas.

Em suas análises, Lima (2014) ressalta a importância dos recursos didáticos enquanto elementos qualificadores da prática educativa e produtores de novos saberes e estratégias de ensino por parte dos professores cursistas. Do ponto de vista da possível construção de saberes, o autor considera, através dos feedbacks dos questionários, que a utilização destes recursos educacionais oportunizou a ampliação dos conhecimentos dos cursistas na temática abordada.

Percebemos, no entanto, uma abordagem bastante aproximada dos tradicionais processos de formação docente, uma vez que os recursos didáticos estavam prioritariamente direcionados às dimensões disciplinares da temática e, também, por não identificarmos no texto, momentos de reflexão e mobilização de saberes individuais e coletivos sobre a prática docente no contexto da utilização dos recursos disponibilizados.

A dissertação Iniciando a docência: a construção do perfil profissional na visão dos futuros professores de ciências da UFPEL, de autoria de Caciele Guerch Gindri de Bastos, teve por objetivo verificar o perfil do professor de ciências que está sendo constituído na Universidade Federal de Pelotas com base nos saberes sendo construídos neste espaço.

Do ponto de vista metodológico, esta investigação segue os moldes da pesquisa qualitativa e se organiza como um estudo de caso. As coletas de dados foram realizadas na disciplina de Estágio Supervisionado do $7^{\circ}$ semestre da licenciatura em Ciências Biológicas através de questionários aplicados aos acadêmicos da turma e observação da prática pedagógica de dois acadêmicos escolhidos de acordo com as respostas destes no questionário.

Em suas análises, a autora identificou que os acadêmicos consideram como significativos os processos formativos desenvolvidos no curso, tanto do ponto de vista das disciplinas específicas quanto das disciplinas pedagógicas. Porém, algumas fragilidades no que se refere às relações entre estas disciplinas foram consideradas como uma barreira nas interações entre 
os conteúdos científicos e a prática docente. Estas fragilidades foram confirmadas nas observações das aulas dos dois estudantes. Esta situação é justificada pela autora por ser uma etapa que se caracteriza, para muitos licenciandos, como a primeira experiência docente, um marco na relação entre os conhecimentos até então teóricos, com as práticas de ensino.

A partir disto, Bastos (2015) avalia que a formação inicial deve se constituir como um espaço de constante aproximação com a realidade das escolas, de modo a potencializar a construção de saberes que subsidiem as práticas destes professores em formação inicial. Neste sentido, as vivências dos estudantes no estágio supervisionado foram apontadas como importantes momentos para a constituição do perfil docente destes professores em formação.

A tese de doutorado intitulada Relações entre saberes e ações na constituição da atividade e prática docentes de professores de ciências, de autoria de Ana Lucia Gomes Cavalcanti Neto, objetivou analisar a prática docente a partir da manifestação dos professores sobre esta, bem como investigar a mobilização dos saberes na ação desses profissionais a fim de identificar e sistematizar os aspectos que constituem a prática docente.

A fim de atingir estes objetivos o desenho metodológico desta investigação seguiu os princípios da pesquisa qualitativa, sendo organizada em três etapas (exploratória, entrevista semiestruturada e observação em sala de aula) e em dois contextos (Brasil e Canadá), tendo como sujeitos da pesquisa os professores das áreas das ciências da natureza.

A autora expressou suas análises em três momentos específicos, sendo eles: sentidos atribuídos à prática e fatores influenciadores dos sentidos; análise da atividade docente a partir da fala do professor de ciências; e, a análise da dinâmica discursiva da sala de aula.

No que se refere às análises dos sentidos atribuídos pelos professores às suas práticas, a autora apontou que, de modo geral, as práticas são idealizadas pelos docentes como os momentos de interação com os estudantes com vistas à aprendizagem. A autora identifica também sentidos específicos atribuídos pelos professores às suas práticas, tais como aqueles relacionados ao desenvolvimento pessoal ou profissional.

Ao analisar a atividade docente a partir da fala do professor de ciências e sistematizar os aspectos que constituem a atividade docente declarada, a autora identifica elementos em comum nos discursos dos professores, tais como a relação que estes profissionais fazem a respeito da 
evolução de suas práticas com a experiência, o domínio dos conteúdos específicos e a participação em cursos de formação continuada.

As análises das interações discursivas da aula de um de seus entrevistados demonstraram para a autora que, em meio a intenções, abordagens e intervenções, saberes são mobilizados para mediar a relação entre os sujeitos e os objetos do conhecimento.

A partir destas considerações é possível perceber a importância que os processos formativos adquirem ao explicitar certos conhecimentos tácitos dos professores de Biologia, saberes estes oriundos da experiência e do contexto de ensino não estão sistematizados e publicizados com frequência, conhecimentos que muitas vezes são guardados na inconsciência ou no não reconhecimento enquanto saberes, mas ricos em potencialidades pedagógicas.

A dissertação Saberes docentes na formação inicial de professores para a educação profissional técnica de nível médio, de autoria de Fernanda Rebeca Araújo da Silva, teve por objetivo compreender em que aspectos as ações desenvolvidas na licenciatura possibilitam a construção de saberes docentes para a Educação Profissional e Tecnológica de nível médio.

Esta investigação teve como lócus as licenciaturas em Ciências Biológicas, Química, Física e Matemática do Instituto Federal de Educação, Ciência e Tecnologia do Amazonas e tiveram como postura metodológica os pressupostos teóricos e epistemológicos da pesquisa qualitativa, tendo a pesquisa-ação como estratégia para as abordagens.

No decorrer desta investigação foi implementado um espaço formativo denominado como "Curso de Curta Duração" que objetivou refletir a EPT e suas bases teórico-metodológicas com os licenciandos sujeitos da pesquisa.

As coletas de dados ocorreram a partir de duas fontes: o diagnóstico realizado nos encontros das disciplinas de Estágio Supervisionado e do Pibid Química e; no Curso de curta duração. Nestes momentos, as coletas de dados se deram através da observação participante, tendo como instrumentos o diário de campo, as filmagens e as gravações de áudio. Foram utilizadas para análise destes dados as abordagens da Análise Textual Discursiva.

Em suas análises a autora identifica que os licenciandos percebem a EPT como um contexto educativo bastante distinto de qualquer outro, o que exige do docente a habilidade de 
lidar com a diversidade dos momentos educativos a fim de atribuir sentido aos conhecimentos de suas disciplinas nos mais diversos cursos.

Quanto à estrutura curricular dos cursos de licenciatura focos do estudo, a autora identifica a falta de interrelação entre as licenciaturas analisadas e as especificidades relativas à EPT, indicando que, embora contemplada em determinadas disciplinas, a complexidade da formação humana omnilateral necessita ser fomentada de forma mais abrangente nos cursos de formação de professores nos Institutos Federais.

A dissertação Saberes docentes produzidos e mobilizados na formação de professores de Ciências Biológicas em cursos de graduação do PARFOR/UFAM, de autoria de Edilene da Silva Souza, foi uma produção que teve por objetivo analisar as contribuições da licenciatura em Ciências Biológicas vinculado ao PARFOR da Universidade Federal do Amazonas no que se refere à construção de saberes dos professores da rede pública participantes do projeto.

Do ponto de vista metodológico, esta investigação se apoiou nos princípios e abordagens da pesquisa qualitativa. As coletas de dados ocorreram em quatro etapas: análise documental do PPC do curso; entrevista com o coordenador do curso; aplicação de questionários aos professores cursistas; e, a realização de entrevistas semiestruturadas com os cursistas que aceitaram o convite para tal atividade.

Em suas análises, Souza (2016) identifica nos documentos orientadores do PARFOR a missão deste programa enquanto política emergencial, que visa suprir as lacunas históricas na formação de professores no país. De acordo com as falas dos professores-cursistas, embora o programa apresente dificuldades de implantação no contexto amazonense, principalmente no que se refere aos modos de oferta e condições de funcionamento, este vem se constituindo como um espaço de discussão, aprendizagens e trocas de saberes. A autora questiona, no entanto, a ausência da dimensão experiencial dos participantes na constituição do curso.

A dissertação Saberes docentes e suas relações com a construção de movimentos epistêmicos desenvolvidos em aulas de Biologia, de autoria de Karla Jeane Coqueiro Bezerra, foi uma produção que teve por objetivo compreender as relações entre os saberes docentes construídos e mobilizados por licenciandos de Ciências Biológicas participantes do Pibid e os movimentos epistêmicos elaborados por estes em suas práticas. 
Metodologicamente, esta investigação se caracteriza como um estudo de caso e segue os pressupostos da pesquisa qualitativa. As coletas de dados ocorreram do acompanhamento do planejamento semestral dos acadêmicos participantes do Pibid; da observação das aulas ministradas pelos licenciandos e; da avaliação das atividades realizadas pelos acadêmicos.

A partir das análises dos dados coletados e sistematizados durante a investigação, Bezerra (2017) identificou, nos acompanhamentos que realizou dos momentos de planejamento e de avaliação das práticas dos estudantes, que ao compartilharem suas experiências, reavaliavam suas ações e concepções sobre o ensino e suas práticas. Tal movimento reforça a ideia de relação entre os saberes e as práticas dos licenciandos, oportunizando a construção e as reconstruções dos diversos saberes necessários ao enfrentamento das situações cotidianas do trabalho docente.

A tese de Raquel Alexandre Pinho dos Santos, intitulada Resistências e emergências nas licenciaturas de Biologia: discursos e práticas sobre sexualidade e gênero, foi uma produção que objetivou compreender a forma como as licenciaturas em Ciências Biológicas na cidade do Rio de Janeiro se estruturam e abordam as temáticas relacionadas a gênero e sexualidade, bem como identificar as professoras universitárias que abordam esses temas na formação inicial de professores, identificando os saberes docentes que estas mobilizam em suas abordagens.

Do ponto de vista metodológico, esta investigação foi organizada a partir dos pressupostos e abordagens da pesquisa qualitativa, utilizando de levantamentos bibliográficos e entrevistas semiestruturadas como fontes de dados para a investigação.

Em suas análises, a autora identificou que, em sua maioria, as licenciaturas em Biologia investem na construção de saberes docentes nas temáticas de gênero e sexualidade, porém, as dimensões éticas e psicológicas são pouco exploradas nos documentos organizadores dos cursos. A autora identifica também que, mesmo em cursos que não contemplam essas temáticas em seus currículos, há o investimento docente na formação dos licenciandos nesses temas. Nos casos em que as temáticas são contempladas na organização dos cursos, as mesmas emergem da intenção das instituições de ensino em formar práticas reflexivas e teoricamente sólidas para o trabalho de temas efervescentes no cenário social e acadêmico.

A dissertação $O$ museu de ciência como cenário da formação docente: saberes e concepções de licenciandos mediadores do Museu Seara da Ciência - UFC, de autoria de Maria Cleidiane Barbosa da Silva, foi uma produção que teve por objetivo compreender as 
contribuições do Museu Seara da Ciência para a formação do professor das áreas das Ciências da Natureza, de modo a compreender de que forma os saberes mobilizados pelos licenciandos durante suas mediações no museu se relacionam com a construção de seus saberes docentes.

Do ponto de vista metodológico, esta investigação se alicerçou sobre as premissas da pesquisa qualitativa nos moldes de um estudo de caso. Foram sujeitos desta pesquisa seis acadêmicos bolsistas que realizam as mediações no referido museu. As coletas de dados se deram através de três fontes: a análise documental, levando em consideração os editais se seleção de projetos para concessão de bolsas e formulários de solicitação e cadastro de propostas de extensão para o museu; as observações sistemáticas das atividades de divulgação científica realizadas pelos bolsistas e; as entrevistas semiestruturadas com os seis acadêmicos.

Em suas análises, a autora identifica o potencial do museu enquanto espaço formativo para os licenciandos, uma vez que os saberes identificados durante as observações das ações educativas no ambiente do museu não se restringem às atividades deste espaço. Neste sentido, a autora observou a construção e mobilização dos saberes que Tardif (2008) descreve como disciplinares e da formação profissional, evidenciando assim a multiplicidade dos espaços em que estes saberes são constituídos, demonstrando também a pluralidade destes saberes.

O potencial formativo deste espaço foi observado também nas reflexões e discussões entre os bolsistas e os coordenadores das áreas de Biologia e Química do museu. Porém, estes momentos se dão de maneira aleatória, não sendo organizados como momentos formais de reuniões e reflexões, situação pode fragilizar este potencial formativo.

A tese de Elizângela Beneval Bento, intitulada Avaliação da aplicação de uma ferramenta pedagógica para o estudo do fumo passivo com os licenciandos em biologia da Universidade Regional do Cariri, CE, é uma produção que teve por objetivo identificar a percepção dos licenciandos de Ciências Biológicas da Universidade Regional do Cariri sobre a ferramenta pedagógica em formato de gibi denominado Pulmão e sua turma, bem como analisar as possíveis contribuições desta ferramenta para a formação destes sujeitos.

Do ponto de vista metodológico, foram utilizados os pressupostos da pesquisa qualitativa para o desenvolvimento desta investigação. Foram sujeitos da pesquisa 154 licenciandos do curso de Ciências Biológicas da Universidade Regional do Cariri. Os dados foram coletados 
através de questionários abertos e da observação participante nos encontros presenciais realizados com os sujeitos.

Em suas análises a autora identificou um baixo percentual de respostas positivas quanto à relevância do gibi como ferramenta pedagógica, situação que de acordo com a autora está relacionada à falta de conteúdo no gibi. Esta dificuldade em relacionar as ideias de uma ferramenta lúdica ao cotidiano da prática educativa é vista pela autora como reflexo de uma formação inicial cujo currículo se ancora na tradição tecnicista. Tal situação sinaliza uma forte tendência de práticas que enfocam na construção de saberes disciplinares, realçando a transmissão de informações como, talvez, única estratégia de ensino por parte dos licenciandos.

\section{CONSIDERAÇÕES FINAIS}

A partir do mapeamento e análise das produções acadêmicas que tiveram por foco a construção e mobilização dos saberes docentes em propostas de formação de professores de Biologia foi possível identificar uma grande riqueza e diversidade de trabalhos, de abordagens.

A análise das produções acadêmicas nos permitiu identificar que, em sua maioria, contemplam os processos de formação inicial de professores nas licenciaturas e espaços específicos como o Pibid.

Foi possível perceber também que a temática aparentemente ainda não se consolidou como campo de investigações nas instituições de ensino e PPGs. As produções analisadas apareceram, neste contexto de investigação, de forma isolada nos diferentes espaços de produção científica.

Ressaltamos também a importância das dissertações e teses analisadas nesta investigação como produções que demarcam este campo de estudos no cenário científico, oportunizando assim a abertura de novos caminhos para as futuras produções, bem como novas formas de compreender e conceber a formação dos professores de Biologia para além dos limites tradicionalmente impostos a estes processos.

\section{REFERÊNCIAS}

BASTOS, Caciele Guerch Gindri De. Iniciando a docência: a construção do perfil

Recebido em: 30/05/2021

Aceite em: 13/08/2021 
profissional na visão dos futuros professores de ciências da UFPEL. 2015. Dissertação (Mestrado em Ensino de Ciências e Matemática) - Faculdade de Educação, Universidade Federal de Pelotas, Pelotas, 2015. Disponível em:

<http://repositorio.ufpel.edu.br:8080/handle/prefix/2886>. Acesso em: 30 ago. 2019.

BEZERRA, Karla Jeane Coqueiro. Saberes docentes e suas relações com a construção de movimentos epistêmicos desenvolvidos em aulas de Biologia. 2017. Dissertação (Mestrado em Ensino de Ciências e Matemática), Universidade Federal do Maranhão, São Luís, 2017. Disponível em: <https://tedebc.ufma.br/jspui/handle/tede/tede/1967>. Acesso em: 3 set. 2019.

BORGES, Cecília; TARDIF, Maurice. Apresentação. Educação \& Sociedade, v. 22, n. 74, p. 11-26, 2001. Disponível em:

<https://www.scielo.br/j/es/a/NpBT6gcRCDXvXRNFzVv5Njs>. Acesso em: 5 jul. 2019.

CARVALHO, Mariana Leal Oliveira de Sá. A abordagem das questões ambientais como forma de inserção da educação ambiental no ensino de ciências. 2010. Dissertação (Mestrado em Educação) - Faculdade de Educação, Universidade Federal de Minas Gerais, Belo Horizonte, 2010. Disponível em: 〈http://hdl.handle.net/1843/BUOS-8GZNQ5>. Acesso em: 21 ago. 2019.

CUNHA, Maria Isabel Da. O tema da formação de professores: trajetórias e tendências do campo na pesquisa e na ação. Educação e Pesquisa, [s. 1.], v. 39, n. 3, p. 609-626, 2013. Disponível em: <https://www.scielo.br/j/es/a/NpBT6gcRCDXvXRNFzVv5Njs/?lang=pt>. Acesso em: 15 jul. 2019.

FABRÍCIO, Lucimara; MARTINS, Alisson Antonio. Formação de professores em Ciências e Biologia: uma análise das produções recentes. In: CONGRESSO NACIONAL DE EDUCAÇÃO - EDUCERE, XIII, 2017, Curitiba. Anais eletrônicos... Curitiba: CIERS-ed, 2017. Disponível em: <https://educere.bruc.com.br/arquivo/pdf2017/26555_13683.pdf>. Acesso em: 15 mai. 2021.

FREITAS, Helder Antonio De. Saberes docentes pedagógicos computacionais e sua elaboração na prática. 2012. Dissertação (Mestrado - Programa de Pós-Graduação em Educação. Área de Concentração: Ensino de Ciências e Matemática) - Faculdade de Educação, Universidade de São Paulo, São Paulo, 2012. Disponível em:

<http://www.teses.usp.br/teses/disponiveis/48/48134/tde-18122012-152845/>. Acesso em: 24 ago. 2019.

GAUTHIER, Clermont et al. Por uma teoria da pedagogia: pesquisas sobre o saber docente. 3. ed. Ijuí: Editora Unijuí, 2013.

GHEDIN, Evandro. Hermenêutica e pesquisa em educação: caminhos da investigação interpretativa. In: Seminário Internacional de Pesquisa e Estudos Qualitativos - SIPEQ, 2004, Bauru. Anais eletrônicos... Bauru: EDUSC, 2004. Disponível em: <https://arquivo.sepq.org.br/II-SIPEQ/Anais/pdf/gt1/10.pdf> Acesso em: 15 ago. 2020.

LIMA, Thierry Faria. A temática algas na formação continuada de professores de

Recebido em: 30/05/2021

Aceite em: 13/08/2021 
Biologia : uma experiência na Educação a Distância. 2014. Dissertação (Mestrado em Ciências Biológicas) - Instituto de Biociências, Universidade de São Paulo, São Paulo, 2014. Disponível em: <http://www.teses.usp.br/teses/disponiveis/41/41132/tde-27012015-080723/>. Acesso em: 30 ago. 2019.

MORYAMA, Nayara; PASSOS, Marinez Meneghello; ARRUDA, Sergio De Mello. Aprendizagem da Docência no PIBID-Biologia. Alexandria: Revista de Educação em Ciência e Tecnologia, [s. 1.], v. 6, n. 3, p. 191-210, 2013. Disponível em: <https://periodicos.ufsc.br/index.php/alexandria/article/view/38157>. Acesso em: 28 out. 2019.

NETO, José Firmino de Oliveira; SANTANA, Aline Neves Vieira; SHUVARTZ, Marilda. A formação de professores (as) em ciências biológicas. Revista Insignare Scientia - RIS, v. 1, n. 1, p. 1-16, 2018. Disponível em:

<https://periodicos.uffs.edu.br/index.php/RIS/article/view/7660>. Acesso em: 2 fev. 2021.

OLIVEIRA, Rosilene dos Santos et al. Mapeando a pesquisa em Ensino de Ciências: um olhar para as linhas de investigação no ENPEC na década de 2010. Revista Insignare Scientia - RIS, [s. 1.], v. 4, n. 3, p. 563-581, 2021. Disponível em: <https://periodicos.uffs.edu.br/index.php/RIS/article/view/12147>. Acesso em: 12 maio. 2021.

RICOEUR, Paul. Interpretação e ideologias. Rio de Janeiro: Francisco Alves, 1990.

ROMANOWSKI, Joana Paulin; ENS, Romilda Teodora. As pesquisas denominadas do tipo “estado da arte" em educação. Revista Diálogo Educacional, v. 6, n. 19, p. 37-50, 2006. Disponível em: <https://periodicos.pucpr.br/index.php/dialogoeducacional/article/view/24176>. Acesso em: 15 ago. 2019.

SANTOS, Wildson Luiz Pereira Dos. Educação científica na perspectiva de letramento como prática social: funções, princípios e desafios. Revista Brasileira de Educação, v. 12, n. 36, p. 474-492, 2007. Disponível em:

<https://www.scielo.br/j/rbedu/a/C58ZMt5JwnNGr5dMkrDDPTN>. Acesso em: 5 fev. 2020.

SEVERINO, Antônio Joaquim. Metodologia do trabalho cientico. 23. ed. São Paulo: Cortez, 2007.

SILVA, Vania Fernandes; BASTOS, Fernando. Formação de professores de ciências: reflexões sobre a formação continuada. Alexandria: Revista de Educação em Ciência e Tecnologia, v. 5, n. 2, p. 150-188, 2012. Disponível em: https://periodicos.ufsc.br/index.php/ alexandria/article/view/37718>. Acesso em: 15 mar. 2021.

SOUZA, Edilene da Silva. Saberes docentes produzidos e mobilizados na formação de professores de ciências biológicas em cursos de graduação do PARFOR/UFAM. 2016. Dissertação (Mestrado em Ensino de Ciências e Matemática), Universidade Federal do Amazonas, Manaus, 2016. Disponível em: <https://tede.ufam.edu.br/handle/tede/5100>.

Recebido em: 30/05/2021

Aceite em: 13/08/2021 
Acesso em: 3 set. 2019.

TARDIF, Maurice. Saberes docentes e formação profissional. 9. ed. Petrópolis: Vozes, 2008.

TAVARES, Fernanda Reis do Pinho. Profissão docente: visões de licenciandos de Ciências Biológicas em diferentes contextos. 2008. Dissertação (Mestrado em Educação) - Faculdade de Educação, Universidade Federal de Minas Gerais, Belo Horizonte, 2008. Disponível em: <http://hdl.handle.net/1843/FAEC-85KJV6>. Acesso em: 19 ago. 2019.

TRIVIÑOS, Augusto Nibaldo Silva. Introdução à pesquisa em ciências sociais: a pesquisa qualitativa em educação. São Paulo: Atlas, 1987.

Recebido em: 30/05/2021

Aceite em: 13/08/2021 